\title{
Properties of Melt-Grown ZnSe Solid-State Radiation Detectors
}

\author{
E.E. Eissler*, K.G. Lynn** \\ * eV PRODUCTS, div. of II-VI Incorporated, 375 Saxonburg Blvd., Saxonburg, PA 16056 \\ ** Brookhaven National Laboratory ${ }^{1}$, Department of Physics, Upton, NY 11973
}

\begin{abstract}
Zinc Selenide' $(\mathrm{ZnSe})$ crystals grown using the High Pressure Bridgman (HPB) technique were used to fabricate solid-state radiation detectors measuring $10 \times 10 \times 2 \mathrm{~mm}^{3}$. Sputtered platinum and gold contacts were applied to polished detector blanks. Voltage versus current characteristics were determined for the devices at $25^{\circ} \mathrm{C}$. Pulse height spectra were obtained using ${ }^{241} \mathrm{Am}$ and ${ }^{109} \mathrm{Cd}$ at both $25^{\circ} \mathrm{C}$ and $150^{\circ} \mathrm{C}$ with applied bias of $9000 \mathrm{~V} / \mathrm{cm}$. Current versus temperature was measured over the temperature range of $30^{\circ} \mathrm{C}$ to $150^{\circ} \mathrm{C}$. Performance was measured at energies of 22.1 and $59.5 \mathrm{keV}$ over a temperature range of $-70^{\circ} \mathrm{C}$ to $170^{\circ} \mathrm{C}$. Current versus dose rate was measured with $662 \mathrm{keV}$ gamma irradiation. A value of the Mobility-Lifetime product $(\mu \tau)$ for electrons was estimated. Time and temperature dependence of photo-peak position using Pulse Height Analysis (PHA) was studied.
\end{abstract}

\section{INTRODUCTION}

Of the II-VI semiconductors, only Cadmium Telluride (CdTe) and Cadmium Zinc Telluride ( $\mathrm{CdZnTe}$ ) have been developed as practical, room temperature, solid state radiation detectors. A useful operating temperature of these detectors is limited, however, to approximately $70^{\circ} \mathrm{C}$ and storage temperatures above $100^{\circ} \mathrm{C}$ can cause irreversible damage. Zinc Selenide (ZnSe), a II-VI semiconductor with a room temperature band gap of $2.7 \mathrm{eV}$, compared to CdTe at $1.47 \mathrm{eV}$, should have a potential to operate at lower bias currents and higher temperatures. Other workers have fabricated detectors from Cadmium Zinc Selenide $\left(\mathrm{Cd}_{0.7} \mathrm{Zn}_{0.3} \mathrm{Se}\right)$ using the Temperature Gradient Solution Zoning technique[1]. Our work details preliminary results obtained with detectors fabricated from $\mathrm{ZnSe}$ crystals produced from the HPB growth technique. The results of this work focus on the possibility of using $\mathrm{ZnSe}$ detectors for high temperature applications.

\section{EXPERIMENTAL DETAILS}

\section{A. Crystal Growth}

ZnSe was grown in a High Pressure Bridgman (HPB) furnace at $\mathrm{eV}$ Products. High purity, pre-reacted $\mathrm{ZnSe}$ pieces

\footnotetext{
'This work was supported in part by DOE under CRADA No. BNLC-94-12.
}

were placed in a $90 \mathrm{~mm}$ diameter graphite crucible. The ampoule, under a $100 \mathrm{~atm}$ over pressure, was heated to $1600^{\circ} \mathrm{C}$ and dropped at $1 \mathrm{~mm} /$ hour from the melt zone.

\section{B. Material Characterization}

The resulting $90 \mathrm{~mm}$ diameter $\times 130 \mathrm{~mm}$ long ingot was sliced using a diamond inside diameter saw to produce both $<111>$ oriented single crystal and randomly oriented polycrystalline slices $2 \mathrm{~mm}$ thick. The pieces were inspected for visible twinning. The following methods were used to characterize representative samples:

1. Double Crystal Rocking Curves (DCRC) were generated using $\mathrm{CuK}_{\alpha}$ radiation, conditioned using a $<111>$ InSb first crystal. Spot size was $2 \mathrm{~mm} \times 2 \mathrm{~mm}$.

2. X-ray topographs were produced using $\mathrm{CuK}_{\alpha}$ radiation conditioned with an asymmetrically cut silicon crystal operating in the magnification mode.

\section{Detector Fabrication}

Blanks $10 \mathrm{~mm} \times 10 \mathrm{~mm}$ in area were inspected for defects and polished on six sides with $1 \mu \mathrm{m}$ alumina grit followed by $0.25 \mu \mathrm{m}$ diamond grit . Direct Current sputtering was used to apply platinum or gold contacts on the two large area faces of each detector, producing a Metal-SemiconductorMetal arrangement (MSM).

\section{Detector Characterization}

All performance tests were conducted on detectors without protective coatings or atmospheres on exposed surfaces:

1. Pulse Height Analysis (PHA) was conducted using an $\mathrm{eV}$ Products 550/5093 pre-amplifier and a Canberra 2020 spectroscopy amplifier. Elevated temperature PHA studies were performed by heating the detectors in a brass test fixture with a $\mathrm{Be}$ entry window. The apparatus was arranged to keep the preamplifier near room temperature.

2. $\mu \tau$ for electrons at $25^{\circ} \mathrm{C}$ was estimated using the photopeak position method. $59.5 \mathrm{keV}$ gamma radiation was directed to the negative contact of a biased detector. Photopeak position versus bias voltage was fitted to the Hecht relationship [2]

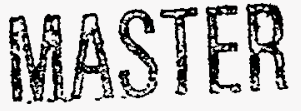


3. Current measurements at $\leq 1100$ volts bias were made with a Keithley 237 high voltage source/measure instrument. A Keithley 417 electrometer was used to measure voltage drop across a $1 \mathrm{G} \Omega$ resistor in series with the detector under test to determine detector currents at $>1100$ volts bias.

4. DC current versus ${ }^{137} \mathrm{Cs}$ dose rate measurements were performed at $25^{\circ} \mathrm{C}$ using a Keithley 237 high voltage source/measure instrument and a calibrated ${ }^{137} \mathrm{Cs}$ test facility $^{2}$ Dose rate was varied by placing the detector at calibrated distances from the source.

\section{RESULTS AND DISCUSSION}

\section{A. Crystal Quality}

The DCRC of Fig. 1, with a Full Width Half Maximum (FWHM) of 160 arc-seconds, is indicative of poor crystalline quality. Likewise the X-ray topograph of the same sample (Fig. 2) indicates 2 variants of dense striation indicating heavy dislocation densities. $\mathrm{ZnSe}$ undergoes a phase transformation just below the melting point from a hexagonal to cubic structure[3]. This transformation may be largely responsible for degradation of crystallinity.

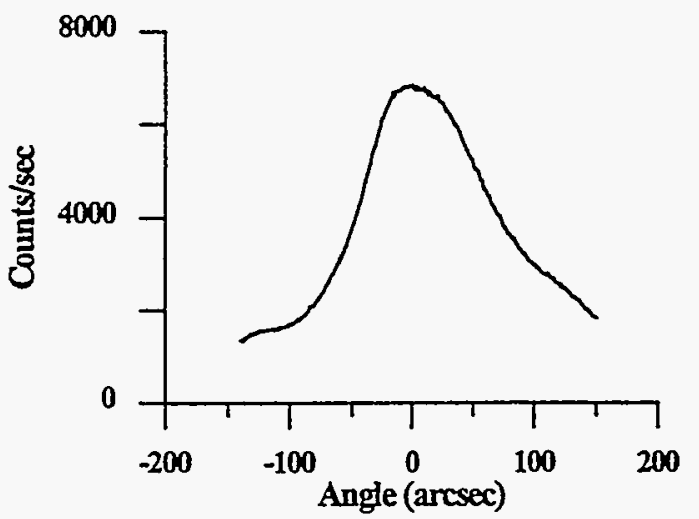

Fig. 1 DCRC of typical ZnSe sample (HPB3-9-1), FWHM $=160$ arcsec.

\section{B. Dark Current Characteristics}

Fig. 3 shows the current versus voltage characteristic for a typical $10 \mathrm{~mm} \times 10 \mathrm{~mm} \times 2 \mathrm{~mm}$ detector at $25^{\circ} \mathrm{C}$. In order to investigate if the Pt contacts form a barrier with the $\mathrm{ZnSe}$ at room temperature, a device was irradiated with $14 \mathrm{keV} \mathrm{X-}$ rays at $55 \mathrm{Rad} /$ hour with 0 volts applied bias. The resultant current was $-3 \times 10^{-12}$ amps compared to $2.1 \times 10^{-11}$ amps when biased at +5 volts with the same irradiation. This implies the existence of a barrier and non-ohmic contacts. The formation of an injecting contact between gold and $\mathrm{ZnSe}$ has been reported by others[4]. It is possible that the Pt contact

2 We would like to acknowledge The Project Manager, Nuclear Biological Defense Systems, United States Army, for use of their radiation dosimeter test facility forms an injecting contact in this case. Fig. 4 shows the current versus temperature characteristic of the same detector with an applied bias of 1000 volts.

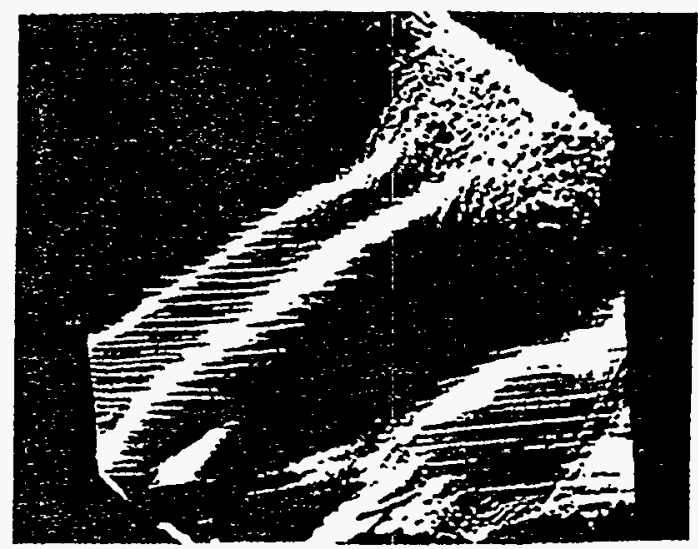

Fig. 2 X-ray topograph of ZnSe sample HPB3-9-1

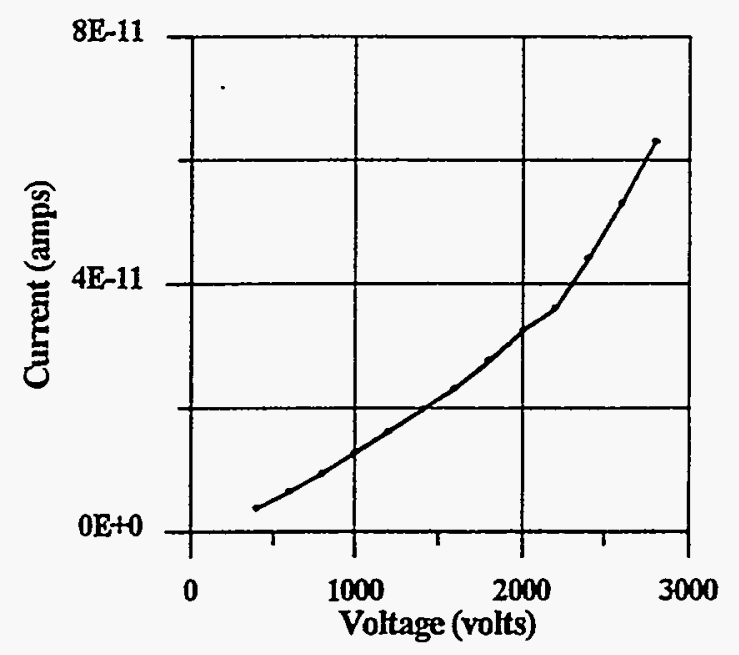

Fig. 3 Current vs. voltage characteristic of $\mathrm{ZnSe}$ detector.

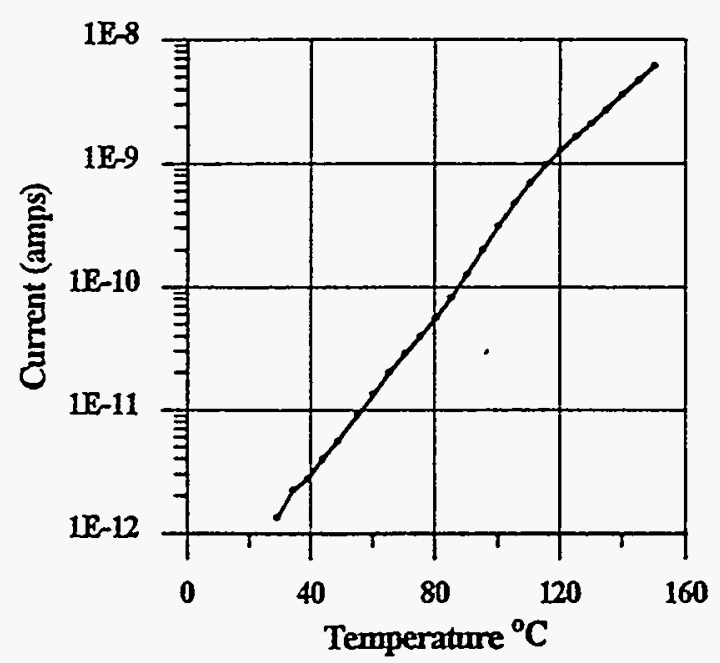

Fig. 4 Current vs. temperature characteristic of $\mathrm{ZnSe}$ detector. Bias $=1000$ volts. 


\section{DISCLAIMER}

Portions of this document may be illegible in electronic image products. Images are produced from the best available original document. 

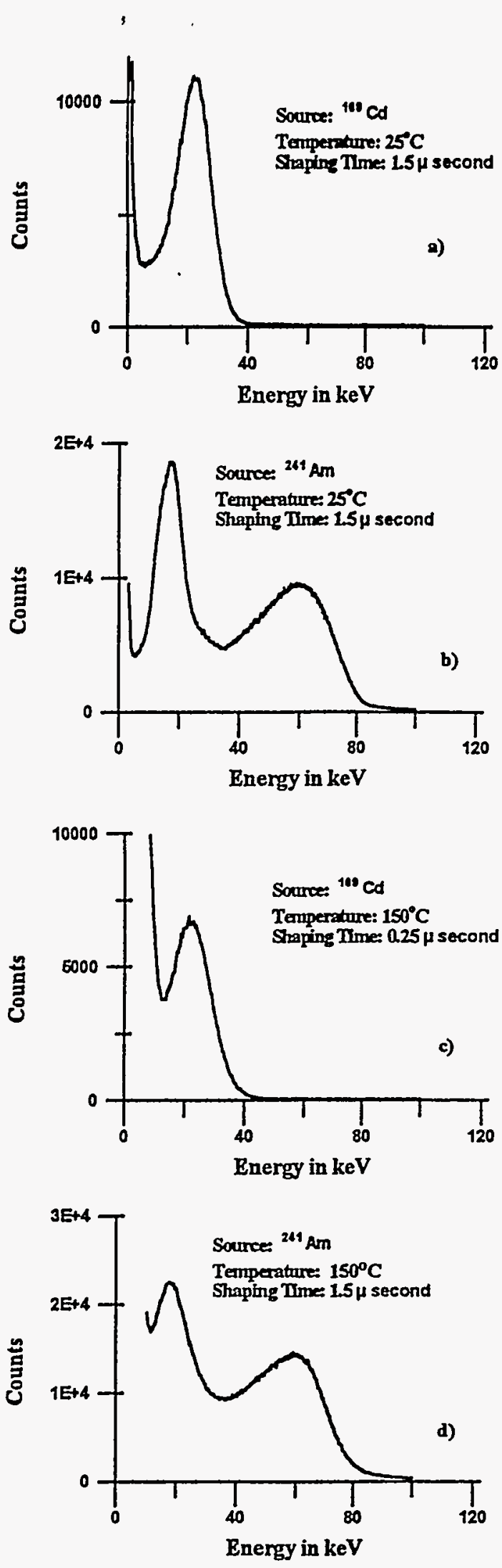

Fig. 5. a,b,c,d PHA analysis of detector at $25^{\circ} \mathrm{C}$ and $150^{\circ} \mathrm{C}$

\section{Pulse Height Spectrum Analysis}

At room temperature the best conditions for PHA were determined to be $900-1000 \mathrm{~V} / \mathrm{mm}$ bias, and $1.5 \mu \mathrm{s}$ shaping time. PHA spectra for typical detectors at $25^{\circ} \mathrm{C}$ (Fig. 5a, b) exhibited $6 \mathrm{keV}$ energy thresholds and resolutions of approximately $50 \%$. Some detectors exhibited resolutions of $25 \%$ at $22.1 \mathrm{keV}$ (Fig. 6) and $35 \%$ at $130^{\circ} \mathrm{C}$. At $160^{\circ} \mathrm{C}$, the energy threshold increased to approximately $17 \mathrm{keV}$ (Fig. $5 c, d)$. Shaping times of $0.25 \mu \mathrm{s}$ were more desirable at temperatures greater than $150^{\circ} \mathrm{C}$ due to increased current noise. Evaluation at temperatures above $175^{\circ} \mathrm{C}$ was precluded by a breakdown of the detector signal. It was not determined if the breakdown occurred within the detector, the mounting, or BNC connectors used in the connection to the preamplifier.

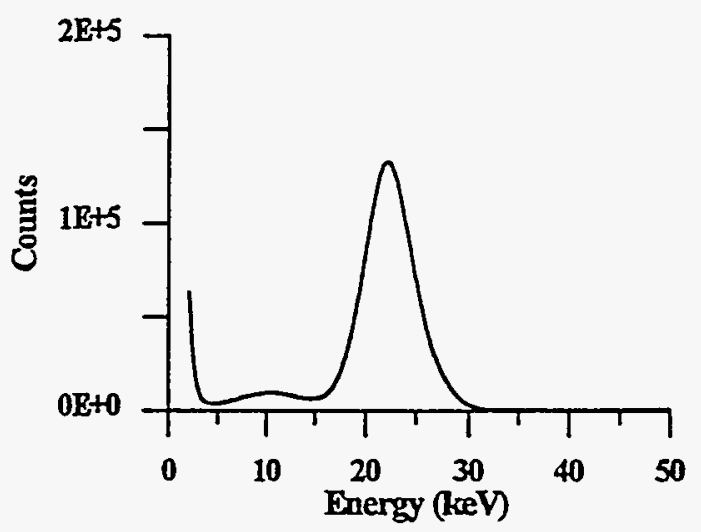

Fig. 6 Spectrum of device with $25 \%$ resolution at $22.1 \mathrm{keV}$. Bias = $2000 \mathrm{~V}$, shaping time $=1.5 \mathrm{usec}, \mathrm{T}=25^{\circ} \mathrm{C}$

Photo-peak position versus energy for a typical detector at $125^{\circ} \mathrm{C}$ is summarized in Fig. 7. Higher energy peaks were not included because centroid determination was ambiguous. Detectors exhibited energy linearity between 18 and $32 \mathrm{keV}$.

Photo-peak position is a function of both temperature and elapsed time after application of bias. The photo-peak position remained constant in the range of $-70^{\circ} \mathrm{C}$ to $100^{\circ} \mathrm{C}$ and decreased by approximately $31 \%$ at $150^{\circ} \mathrm{C}$ when measured at a constant shaping time of $1.5 \mu \mathrm{s}$ (Fig. 8).

At $40^{\circ} \mathrm{C}$, photo-peak position decreased for a period of approximately $10^{3}$ seconds after bias was applied (Fig. 9). At temperatures above $100^{\circ} \mathrm{C}$ the time to reach stable operation decreased, but over long periods of time at elevated temperatures, the decrease continued slowly (Fig. 10). It is suspected that oxidation of the edges of the detector played a role in this long term degradation. When the detector edges were cleaned with acetone after the detector had been at high temperature for a long period of time, the photo-peak positions retumed to the same channels occupied before the heating cycle. 


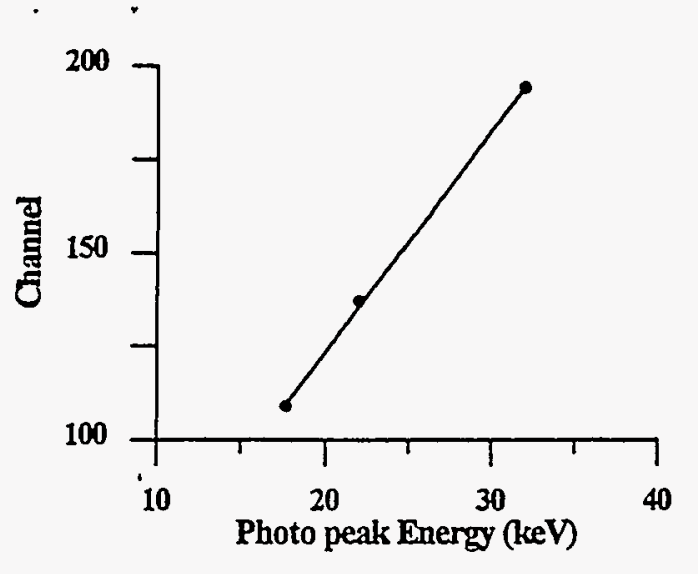

Fig. 7 Photo-peak energy vs. photo-peak position. $\mathrm{T}=125^{\circ} \mathrm{C}$, Photo-peak energies: ${ }^{241} \mathrm{Am}, 17.7 \mathrm{keV} ;{ }^{105} \mathrm{Cd}, 22.1 \mathrm{keV} ;{ }^{137} \mathrm{Cs}, 32.1$ $\mathrm{keV}$.

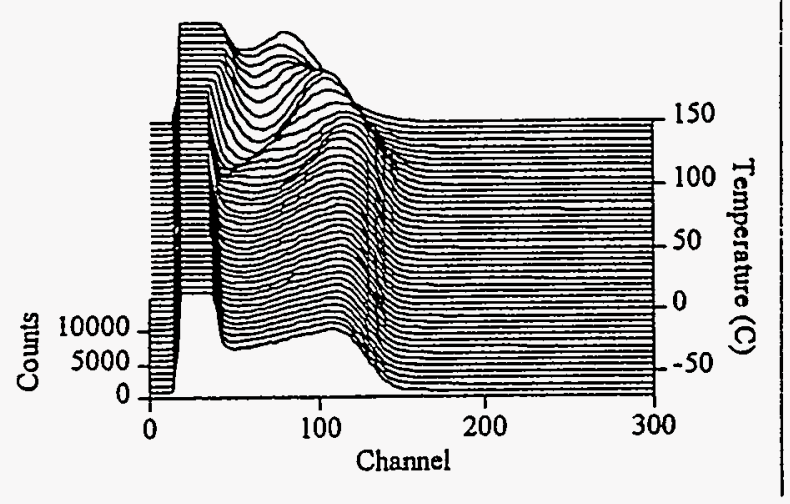

Fig. 8 Photo-peak position : $-70^{\circ} \mathrm{C}$ to $150^{\circ} \mathrm{C}$, Bias $=1000 \mathrm{~V}$, Shaping time $=1.5 \mu \mathrm{sec}$.

\section{D. $\mu \tau$ For Electrons}

Fitting the Hecht equation to the $59.5 \mathrm{keV}$ gamma photopeak position data yielded an estimate of $\mu \tau$ for electrons at $25^{\circ} \mathrm{C}$ of $4 \times 10^{-5} \mathrm{~cm}^{2} /$ Volt.

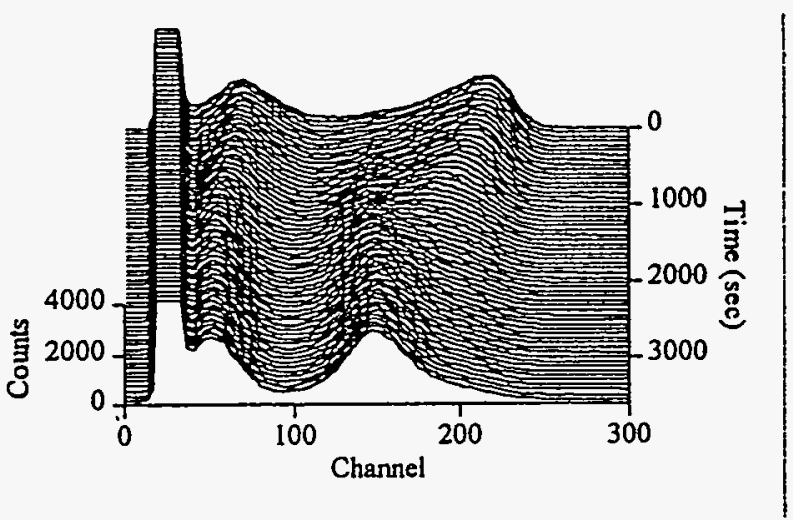

Fig 9. Photo-peak position: $\mathrm{T}=40^{\circ} \mathrm{C}, \mathrm{Bias}=1000 \mathrm{~V}$ at $00 \mathrm{sec}$, Shaping time $=1.5 \mu \mathrm{sec}$.

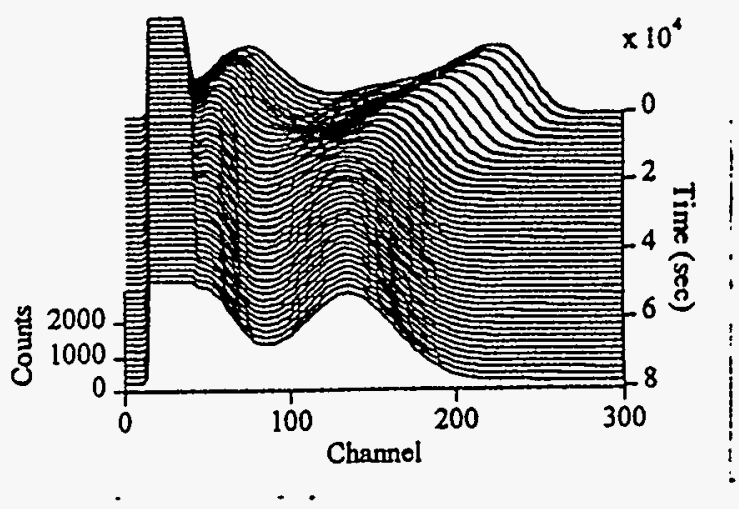

Fig. 10 Photo-peak position: $\mathrm{T}=100^{\circ} \mathrm{C}, \mathrm{Bias}=2000 \mathrm{~V}$ at $\triangleright 0 \mathrm{sec}$ Shaping time $=1.5 \mu \mathrm{sec}$.

\section{E. Current Mode Operation}

A $10 \mathrm{~mm} \times 10 \mathrm{~mm} \times 2 \mathrm{~mm}$ detector biased at 5 volts was irradiated with $662 \mathrm{keV} \gamma$-rays at dose rates of 30,60 and 120 Rad/hour. Fig. 11 shows detector current vs. time at $25^{\circ} \mathrm{C}$. At $t=0 \mathrm{sec}$, a mechanical shutter on the radiation source was opened. Response time for the detector to reach a steady state current was on the order of $10 \mathrm{sec}$ while sensitivity was approximately 1 picoamp/rad/hour. At a bias of 1000 volts, sensitivity was increased by a factor of $10^{3}$, but the response time is too large for practical applications. (Fig. 12)

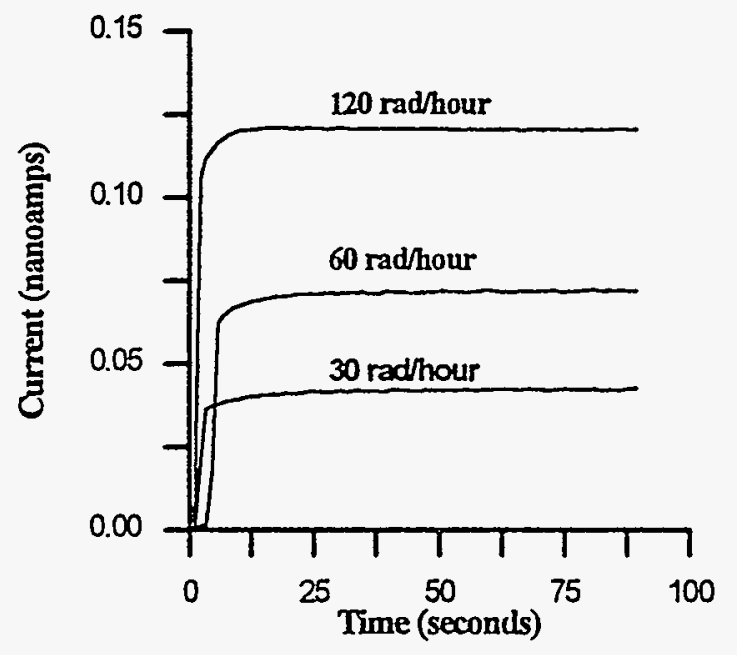

Fig. 11 Current vs. time for various dose rates of $662 \mathrm{keV}$ gamma irradiation. bias $=5$ volts 


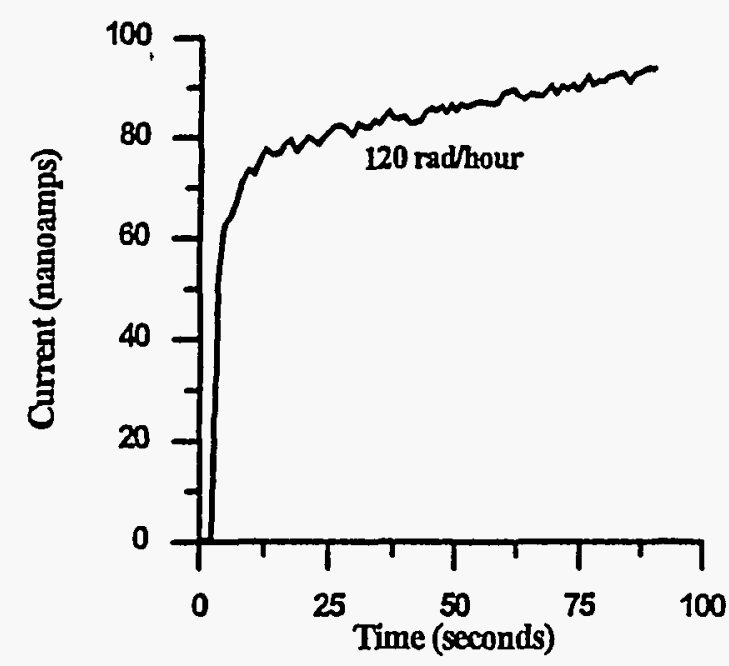

Fig. 12 Current vs, time for various dose rates of $662 \mathrm{keV}$ gamma irradiation. Bias $=1000$ Volts, dose $=120$ Rad.

\section{CONCLUSIONS}

In this paper, we have discussed the possibility of using the II-VI compound semiconductor, $\mathrm{ZnSe}$, for a high temperature $\left(25 \leq \mathrm{T} \leq 160^{\circ} \mathrm{C}\right) \mathrm{x}$-ray or $\gamma$-ray detector. Various properties have been measured and photo-peaks were observed at both 22 and $60 \mathrm{keV}$ over an extended temperature range. Time and temperature dependence of photo-peak position using PHA were measured for various detectors. The details of this behavior are not understood, but some polarization has been observed below $50^{\circ} \mathrm{C}$. Gold contacts were found to be more stable during temperature cycling, and crystals with visible twins appeared to have higher resolution photo-peaks. Further studies are underway to elucidate these novel detectors for various applications.

\section{REFERENCES}

[1] A. Burger, K. Roth and M. Schieber, IEEE TNS, Vol. NS-32, No. 11985

[2] K. Zanio, W. Akutagawa and J. W. Mayer, Appl. Phys. Lett. 11, (1) 5 (1967).

[3] M.P. Kulakov, et al., Sov. Phys. Solid State, Vol. 18 , No. 3, 526-527 (march 1976).

[4] Zmija, Mieczyslaw, et al., Electron Technology 13, 4, pp. $17-29,1982$, Institute of Electron Technology, Warsaw.

\section{DISCLAIMER}

This report was prepared as an account of work sponsored by an agency of the United States Government. Neither the United States Government nor any agency thereof, nor any of their employees, makes any warranty, express or implied, or assumes any legal liability or responsibility for the accuracy, completeness, or usefulness of any information, apparatus, product, or process disclosed, or represents that its use would not infringe privately owned rights. Reference herein to any specific commercial product, process, or service by trade name, trademark, manufacturer, or otherwise does not necessarily constitute or imply its endorsement, recommendation, or favoring by the United States Government or any agency thereof. The views and opinions of authors expressed herein do not necessarily state or reflect those of the United States Government or any agency thereof. 